\title{
Bulk milk ELISA and the diagnosis of parasite infections in dairy herds: a review
}

\author{
Mary Sekiya, Annetta Zintl and Michael L Doherty
}

\begin{abstract}
The bulk milk enzyme-linked immune sorbent assay (ELISA) is a rapid and inexpensive method of assessing herd exposure to pathogens that is increasingly being used for the diagnosis of parasite infections in dairy herds. In this paper, with the dairy herd health veterinarian in mind, we review the principles of the assay and the recent literature on the potential role of bulk milk ELISA for the diagnosis of ostertagiosis, fasciolosis, parasitic bronchitis due to cattle lung worm and neosporosis. It is generally accepted that assay results reflect exposure to the parasite rather than the presence of active infection. Bulk milk ELISA can be a useful tool for the veterinary practitioner as a component of a herd health monitoring programme or in the context of a herd health investigation. It can also play a role in regional or national surveillance programmes. However, the results need to be interpreted within the context of the herd-specific health management, the milk production pattern and the parasite life cycle.
\end{abstract}

Keywords: Bulk milk ELISA, Dairy herds, Parasite infections, Ostertagia, Fasciola, Dictyocaulus, Neospora

\section{Introduction}

This review paper emerged from discussions within the Animal Health Ireland (AHI) Technical Working Group for Parasite Control which identified a need to seek as much scientific clarity as possible in relation to the usefulness of bulk milk testing for parasite infections within the Irish dairy herd. AHI is an industry-led, not-for-profit partnership between livestock producers, processors, animal health advisers and government, with a remit encompassing diseases and conditions of rrlivestock that are endemic in Ireland but which are not currently subject to regulation [1]. Work programmes have been built on the animal health priority areas [2] including parasite control and biosecurity. At the core of each work programme is a Technical Working Group (TWG), or group of experts in the relevant fields. In keeping with the principle of maintaining standards of scientific excellence, the outputs of the working groups are subjected to peer-review and, where possible, published in international peer-reviewed journals.

The enzyme-linked immune sorbent assay (ELISA) is an immune assay which relies on the detection of host antibody as an indicator of infection. Once it has been developed for the analysis of individual serum samples it is

\footnotetext{
* Correspondence: Michael.Doherty@ucd.ie

UCD School of Veterinary Medicine, University College Dublin, Belfield, Dublin 4, Ireland
}

\section{Underlying technology}

ELISA development begins with the identification of parasite-specific antigens that elicit a strong immune response in the host. Once a suitable immunodominant protein antigen has been identified, it can be used to capture parasite-specific antibodies. The gene for the protein may also be cloned and expressed as a pure recombinant protein [7-9]. Recombinant proteins are uniform and can be produced in quantity but they generally represent only one or a few parasite proteins and lack post-translational modifications that may be important for their immunogenicity.

Most bulk milk assays use the indirect ELISA format. Antigen is coated on a microwell plate, the test sample, containing antibodies, is added and antibodies specific to the parasite bind to the antigen. A detection antibody, conjugated to an enzyme, commonly horseradish peroxidase (HRP) that catalyses the conversion of a substrate, results 
in a colour change (optical density) (Table 1) that can be measured using spectrophotometry. Negative samples result in a low optical density (OD) value due to failure to convert substrate and positive samples result in a quantifiable OD reading that is higher than the cut-off $O D$ value (Table 1) [10].

\section{Validation of the ELISA for bovine serum samples}

ELISA assays are validated by comparing results with a 'gold standard' assay (Table 1), which provides indisputable evidence that an animal is infected with the parasite. A 'gold standard' might represent the parasitological detection of eggs, larvae or oocysts in a faecal sample or the verification of disease status by post-mortem examination. Results from the gold standard assay are compared with ELISA scores from the same individuals in order to determine suitable cut-off values that provide the highest possible sensitivity and specificity (Table 1 ). A statistical method that is commonly used for this purpose is the receiver operator characteristic (ROC) (Table 1) [11]. Originally developed to distinguish signal from noise in radio frequencies, the ROC provides a measure of how accurate a test is when compared to the gold standard. Suggest use Sensitivity probability of a positive test result given the animal is truly diseased and the specificity probability of a negative test result given the animal is truly non-diseased [12]. Alternatively, the cut-off value can be determined by testing a pool of known negatives. Suggested cut-offs are given as the mean OD of the known negative samples plus 2 or 3 standard deviations depending on the degree of stringency required [13]. The results from ELISAs are often reported as percent positivity (PP), sample to positive (SP) ratio or optical density ratio (ODR) (Table 1).

\section{Development of the ELISA for individual and bulk milk samples}

In cows, immune responses to infection can be measured in milk as well as in sera. However, antibodies appear earlier in sera than in milk and the concentration of serum antibodies is approximately 30 times greater than in milk [14]. In milk, the predominant immunoglobulin is IgG1 (representing about $80 \%$ of the total immunoglobulin content), which is transported by active receptors on mammary alveolar cells [15]. Individual and bulk milk samples can both be tested by ELISA, however, there are significant differences in the interpretation of the results. Bulk milk samples are pooled samples and represent all lactating animals that contribute to the tank. There are many factors that can affect the titre (Table 1) of parasite-specific antibodies in the bulk milk including the number and relative seropositivity of contributors, stage of infection, stage of lactation, illness due to infection, and milk yield [16].

It is also important to note that a negative result from a bulk milk ELISA does not mean that the herd is definitively free of a particular parasitic infection. All ELISAs have a threshold antibody concentration that must be achieved before the bulk milk assay tests positive. Intuitively, one would assume that the lower the OD value for the bulk milk, the fewer infected animals are contributing antibodies to the pooled sample. However, correlating the percentages of infected animals with a bulk milk score can be challenging. This measurement is known as 'withinherd prevalence, and the minimum within herd prevalence gives an approximate threshold cut-off for a positive test result. There are several approaches to determining within-herd prevalence, the most common is to calculate the percent seropositivity of individual animals contributing to the bulk-tank pool, and to correlate this value with the bulk milk score applying regression analysis $[17,18]$.

\section{Application of bulk milk ELISAs for the diagnosis of infection status and surveillance}

In addition to the factors mentioned above, bulk milk ELISA may be further biased because it clearly does not include contributions from non-lactating animals, those withdrawn from the milking pool due to disease or

Table 1 Explanation of the terminology used in this review

\begin{tabular}{|c|c|}
\hline Term & Explanation \\
\hline Gold standard & A perfect definitive test that produces no misclassifications \\
\hline Sensitivity & Probability of a positive test result given the animal is truly infected \\
\hline Specificity & Probability of a negative test result given the animal is truly not infected \\
\hline Titre & The highest dilution of the sample at which the test is still positive \\
\hline Optical density (OD) & $\begin{array}{l}\text { Colour (absorbance) change in a sample resulting from the conversion of substrate and measured } \\
\text { using spectrophotometry }\end{array}$ \\
\hline Cut-off OD value & The absorbance above which samples are considered positive \\
\hline Receiver operator characteristic & Statistical method used to calculate cut-off OD values \\
\hline $\begin{array}{l}\text { Sample to positive (SP) ratio or Optical density } \\
\text { ratio (ODR) }\end{array}$ & $\begin{array}{l}\text { The ratio of the } \mathrm{OD} \text { of the sample to the } \mathrm{OD} \text { of the positive control } \\
\left(\mathrm{SP} \text { ratio }=\mathrm{OD}_{\text {sample }} / O D_{\text {positive control }}\right)\end{array}$ \\
\hline Percent positivity (PP) & Sample to positive ratio $\times 100$ \\
\hline
\end{tabular}


those treated with substances that require milk withdrawal [16]. Finally, bulk milk ELISA is subject to the same shortcomings as individual serum ELISA because there can be significant delays between onset of an infection and detection of the antibody and/or a lag between the elimination of the parasite and corresponding reduction in antibody titre. These in turn are influenced by treatment, re-infection or host immune response and clearance of the parasite.

Nevertheless, bulk milk ELISA results can provide timely information about parasite exposure status within the larger picture of a herd health monitoring programme. Monitoring on a regular basis (approximately 4 times/year) may demonstrate trends of parasite-specific antibody levels and seasonal variations in disease status. Bulk milk ELISAs can also be useful tools for measuring the relative intensity or prevalence of parasite infection in the herd [19-21].

Vercruysse and Claerebout (2001) [22] reviewed a range of parasitological and immunological techniques used to detect common diseases of livestock in the context of their ability to diagnose clinical and subclinical disease. Three thresholds were proposed: (1) a therapeutic threshold, where animals exhibit clinical signs, (2) a productionbased or economic threshold, where individuals in a herd harbour subclinical infections that affect productivity and (3) a preventive threshold that can be used to predict future infections to inform appropriate control measures. Results from bulk milk assays are effective in determining production-based thresholds since they provide a useful indicator of subclinical infections and the relative infection status of a herd $[8,21,23]$.

\section{Stomach worm, Ostertagia ostertagi Life cycle and clinical signs}

The nematode, O. ostertagi is the most important parasite contributing to bovine parasitic gastroenteritis in temperate and subtropical regions [24]. Eggs shed by infected individuals onto pasture, hatch under suitable environmental temperatures (above $10^{\circ} \mathrm{C}$, optimum $23-25^{\circ} \mathrm{C}$ ) and continue to develop within the faecal pat. As rainfall causes the pat to break up, infective third stage larvae emerge onto the herbage. When a new host ingests the larvae, they moult in the rumen and then burrow into the abomasal gastric glands. Finally adult worms emerge into the lumen of the abomasum. The pathology caused by ostertagiosis is chiefly associated with the larval migratory activity which causes structural and functional changes to the gastric glands, resulting in loss of function and impairment of the digestive process. This is exacerbated by host immune and inflammatory responses to the parasite and its products. Heavy infections are characterised by profuse watery diarrhoea and anorexia resulting in significant loss of body weight and condition. Subclinical infections, on the other hand, have been associated with economic losses due to impaired performance and milk yield [25]. Type I ostertagiosis usually occurs in calves from mid-July and is associated with high morbidity but low mortality. In contrast, type II ostertagiosis is generally seen in yearlings in the subsequent winter or spring. In this case, infections result from the delayed maturation of larvae ingested during the previous autumn. While the numbers of individuals affected by type II ostertagiosis is generally small, mortality rates amongst these may be high unless effective and timely treatment is provided.

\section{ELISA assays for the detection of 0 . ostertagi}

An ELISA originally developed for the detection of serum antibody against $O$. ostertagi was first applied to milk in 1993 [26]. Using adult worm extract as capture antigen, Kloosterman and colleagues noted a significant correlation between bovine serum, individual milk and bulk-tank milk antibody concentrations [26]. Since then Svanovir has developed a commercial product (available from Boehringer Ingelheim Svanova, Uppsala Sweden) which can be used to screen bulk milk samples. The antigen is crude worm extract and results are reported as ODR. The kit also provides a conversion chart (developed by Forbes and Charlier [19]) that links ODR with predicted loss in milk yield and can be used to estimate likely economic losses.

It is important to stress that the relationship between serum, individual milk and bulk milk samples can be complex. A study in Sweden reported that median ODR was less for bulk milk than for serum but greater than those measured for individual milk samples [27]. Assessing individual and bulk milk ELISA ODRs from two dairy herds in Normandy over a one year period, Charlier and co-workers [21] also found that bulk milk ODRs were higher than mean individual milk ODRs. The authors suggested that this may be due to a greater contribution to the bulk milk tank by individuals with high antibody titres. Use of the bulk milk ELISA is further complicated by the fact that the crude antigen assay may cross-react with other bovine helminths, such as Cooperia oncophora and Fasciola hepatica [28].

\section{Association of bulk milk 0 . ostertagi antibody levels with production parameters}

While O. ostertagi is present on all farms, the impact of the parasite on production and the potential value of treatment can be estimated by the level of antibodies detected. A range of studies have confirmed that Ostertagia bulk milk antibody levels are negatively associated with milk yield $[25,27,29-32]$. In addition there may be a small but significant decrease in milk protein content. Bulk milk ELISA scores increased with age of cow and the number of lactations $[25,30,31]$ reflecting higher levels of specific antibody in older cattle [24]. Furthermore, the age at first calving was positively associated with bulk milk antibody levels 
(expressed as ODR) and Holstein herds had higher ODRs compared with Normande or Montbeliard herds [21].

Significant research effort has gone into the development of the Ostertagia bulk milk ELISA as a quantitative test that can be used to predict likely production losses associated with elevated antibody levels in the bulk milk tank. One of the most comprehensive studies by Forbes and colleagues [29] has given rise to the chart mentioned above, which is used in the interpretation of ODR scores for the Svanova Ostertagia ELISA kit [19].

\section{Effects of management practices on bulk milk 0 . ostertagi} antibody levels

As would be expected from the epidemiology of the parasite, the most important management factor affecting antibody levels in the bulk milk tank is the extent to which animals have outdoor access to pasture [19,29,30,32-35]. No access to pasture resulted in low antibody concentrations, while in animals kept outdoors, antibody levels increased with the level of access to fully grassed pasture and herbage. There was also a proportional increase of bulk milk antibody level (measured as ODR) with percent of time spent grazing daily. Herds that were managed by summer grazing and winter housing demonstrated a seasonal pattern of high ODR in late summer and early autumn and low ODR in winter [31,33] reflecting the build-up of parasite larvae on pasture in mid-summer [24]. Furthermore, bulk milk ELISA scores increased the earlier the date of turnout and the later the month of housing [28,29]. Extensive production systems and organic herds with smaller herd sizes and lower stocking densities tend to have higher bulk milk antibody levels than animals in intensively managed systems $[28,29,32,36]$.

Anthelmintic treatment of either the entire herd or milking cows at calving causes a decline in bulk milk ELISA scores [35], however, not all animals in the herd respond to the same degree. Sanchez and co-workers found that highly positive cows showed a greater response to treatment as measured by milk yield [37], than cows with lower levels of milk antibody and recommended using individual, rather than bulk milk testing to predict the milk production response after anthelmintic treatment [38].

While certain climatic variables such as rainfall, temperature and vegetative index also affect bulk milk antibody levels, it is thought that, within a given biome, management practices have a higher potential impact than environmental factors [35]. Prevalence of Ostertagia is significantly higher in central European countries than in Scandinavian countries as shown in Table 2, which may indicate a role of climate in the parasite success.

Prevalence of $O$. ostertagi according to bulk milk ELISA According to two large scale bulk milk surveys, Ostertagia prevalence in Ireland/UK is intermediate-to-high compared
Table 2 Ostertagia ostertagi prevalence based on bulk milk assay

\begin{tabular}{lccc}
\hline $\begin{array}{l}\text { Country } \\
\text { (region) }\end{array}$ & Number of herds & Prevalence & Reference \\
\hline Belgium & Conventional 1,800 & $59.1 \%(95 \% \mathrm{Cl}, 56.8-61.4 \%)$ & {$[39]$} \\
Sweden & Organic 113 & $0.82 \%(95 \% \mathrm{Cl}, 0.78-0.86 \%)$ & {$[36]$} \\
& Conventional 113 & $0.66 \%(95 \% \mathrm{Cl}, 0.61-0.71 \%)$ & \\
\hline
\end{tabular}

with other European countries (Table 3) [29]. It is thought that this is largely due to the high proportion of grass in the cows' diet ( $42 \%$ of herds were fed exclusively on grass, compared with Germany, where grass comprises less than $50 \%$ of the diet of most of the herd). In addition, Ireland with its temperate climate has the longest average grazing season at 7.4 months, (grazing was shortest for Sweden at 4.5 months, with the other countries intermediate).

\section{Liver fluke, Fasciola hepatica}

Life cycle and clinical signs

The liver fluke or Fasciola hepatica is found worldwide in temperate regions and has a complex life cycle that is dependent on an intermediate snail host. Eggs that are passed in the faeces of an infected final host, develop and release motile ciliated miracidia onto the pasture. When the parasite encounters its intermediate host, the amphibious snail Galba truncatula, it penetrates via the integument and develops through the sporocyst and redial stages to the cercaria stage, which is shed by the snail. Following attachment to the vegetation, the cercariae encyst into infective metacercariae. When the final mammalian host ingests metacercariae, they excyst in the small intestine, migrate through the gut wall, and, after crossing the peritoneum, penetrate the liver capsule. Juvenile flukes burrow through the liver parenchyma for 6-8 weeks, then enter the bile ducts (occasionally also the gallbladder) where they reach sexual maturity [24]. Clinical signs resulting from heavy parasite burdens are characterised by anaemia, damage to liver parenchyma and submandibular oedema ('bottle jaw'). In cattle, in contrast to sheep, acute disease

Table 3 Mean optical density ratios (ODR) for Ostertagia ostertagi based on bulk milk assay

\begin{tabular}{lccc}
\hline Country & $\begin{array}{c}\text { Number of herds } \\
\text { pastured/total }\end{array}$ & Mean ODR & Reference \\
\hline Denmark & $146 / 146$ & 0.48 & {$[29]$} \\
Germany & $78 / 131$ & 0.48 & {$[29]$} \\
Italy & $47 / 140$ & 0.31 & {$[29]$} \\
Netherlands & $243 / 288$ & 0.45 & {$[29]$} \\
Portugal & $92 / 163$ & 0.61 & {$[29]$} \\
Spain & $91 / 143$ & 0.53 & {$[29]$} \\
UK/lreland & $142 / 174$ & 0.60 & {$[29]$} \\
\hline
\end{tabular}


Table 4 Performance characteristics and minimum within-herd prevalence for four Fasciola hepatica ELISA kits

\begin{tabular}{|c|c|c|c|c|c|c|}
\hline Kit & Antigen & $\begin{array}{c}\text { Sensitivity } \\
\text { (individual Sera/milk) } \\
\end{array}$ & $\begin{array}{c}\text { Specificity } \\
\text { (individual Sera/milk) } \\
\end{array}$ & $\begin{array}{l}\text { Minimum within } \\
\text { herd prevalence }\end{array}$ & Supplier & Reference \\
\hline \multirow{2}{*}{$\begin{array}{l}\text { IDEXX- Institut } \\
\text { Pourquier }\end{array}$} & \multirow[t]{2}{*}{ Fraction $\mathrm{f} 2$ of $\mathrm{ES}$} & \multirow[t]{2}{*}{$95 \%^{\mathrm{a}}$} & \multirow[t]{2}{*}{$98.2 \%^{a}$} & \multirow[t]{2}{*}{$20 \%^{\mathrm{b}}$} & \multirow[t]{2}{*}{ IDEXX } & ${ }^{a}$ [43] \\
\hline & & & & & & $\mathrm{b}[16]$ \\
\hline \multirow[t]{2}{*}{ MM3-SERO } & \multirow{2}{*}{$\begin{array}{l}\text { Monoclonal Ab sens. wells treated } \\
\text { with purified protein }\end{array}$} & \multirow[t]{2}{*}{$100 \%^{c}$} & \multirow[t]{2}{*}{$100 \%^{c}$} & \multirow[t]{2}{*}{$12 \%^{d}$} & \multirow[t]{2}{*}{ Bio-X } & c [44] \\
\hline & & & & & & ${ }^{d}[41]$ \\
\hline \multirow[t]{2}{*}{ LSTM ES-ELISA } & \multirow[t]{2}{*}{ ES fraction } & \multirow[t]{2}{*}{$98 \%(95 \%$ Cl 96-100\%) } & \multirow[t]{2}{*}{$96 \%(95 \%$ Cl 93-98\%) } & \multirow[t]{2}{*}{$25 \%^{f}$} & In-house & $e^{e}[17]$ \\
\hline & & & & & & ${ }^{f}[45]$ \\
\hline
\end{tabular}

only occurs occasionally, mostly in young calves following heavy challenge. Chronic infections, on the other hand, are common, causing reduced milk yield and quality [24].

\section{ELISA assays for the detection of $F$. hepatica}

Several ELISAs have been developed for the detection of $F$. hepatica infection in bulk milk samples, these include the Idexx ELISA serum and milk kit (formerly the Institut Pourquier ELISA - Idexx, Westbrook Maine, USA) [40], the MM3-Sero ELISA, an ELISA based on a monoclonal antibody, that is used to capture specific F. hepatica 'excretory-secretory' (ES) antigens [41] and the University College Dublin (UCD) assay which relies on a recombinant mutant Cathepsin L1, the immunodominant protein found in ES [9]. However, the most widely used ELISA in published studies is an in-house assay developed at the Liverpool School of Tropical Medicine that uses the ES fraction of the parasite as capture antigen [17]. ES antigens are immune modulatory molecules actively shed from the surface of helminth parasites or released through specialised excretory or secretory organs [42]. Table 4 summarises the different available ELISA formats for bulk milk testing. All kits also have a high sensitivity and specificity for individual sera and milk. The minimum within-herd prevalence levels range from a low of $12 \%$ for the MM3-SERO ELISA to approximately $25 \%$ for the ES-ELISA.

\section{Association of bulk milk $F$. hepatica antibody levels with production parameters}

While most studies agree that elevated F. hepatica antibody levels in bulk-tank milk samples are associated with decreased milk yield [46,47], a reduction in milk solids or fat content has been reported by some workers [46,48]. In addition, herds with higher antibody levels tend to have longer intercalving intervals, reflecting the potentially negative effects of liver fluke infections on conception and pregnancy rates [49]. It is likely that many of these effects are only detectable when comparing highly positive to negative herds [47], indicating that the magnitude of the parasite burden may be fundamental.

In addition to affecting production parameters and thus causing economic losses, $F$. hepatica has been implicated as an immunosuppressive agent. More specifically, the fluke is thought to increase susceptibility to certain bacterial infections and may inhibit the inflammatory response to the intradermal tuberculin test [50].

Reichel and co-workers stated that the issue of the duration of the antibody response in relation to recently treated infections remained unresolved and the persistence of antibodies after treatment could lead to 'false positives' [18]. This point serves to highlight the importance of adopting an overall herd health approach with attention being paid to the cows in the context of clinical and subclinical disease as well as to other diagnostic tests including coprological examination.

\section{Effects of management practices on bulk milk $F$. hepatica antibody levels}

Generally fluke infections cluster in areas where environmental conditions are suitable for the larval life cycle stages and the intermediate host, the mud snail, G. truncatula [39]. However, using bulk milk ELISA screening as an indicator for economically significant liver fluke burdens,

Table 5 F. hepatica prevalence based on bulk milk assay and in comparison to faecal analysis (where available)

\begin{tabular}{|c|c|c|c|c|}
\hline $\begin{array}{l}\text { Country/ } \\
\text { region }\end{array}$ & $\begin{array}{l}\text { Number } \\
\text { of herds * }\end{array}$ & $\begin{array}{c}\text { Herd } \\
\text { prevalence - } \\
\text { Bulk milk }\end{array}$ & $\begin{array}{c}\text { Herd } \\
\text { prevalence - } \\
\text { Faecal analysis }\end{array}$ & Reference \\
\hline England & 623 & $48 \%$ & & [45] \\
\hline Wales & 445 & $86 \%$ & & \\
\hline England & 60 & $53 \%$ & $\begin{array}{c}\text { 17\% (of pooled } \\
\text { samples examined } \\
\text { by standard } \\
\text { sedimentation) }\end{array}$ & [53] \\
\hline Belgium & 1,800 & $\begin{array}{c}37 \%(95 \% \mathrm{Cl}: \\
35-40 \%)\end{array}$ & & [39] \\
\hline \multirow[t]{2}{*}{ Sweden } & $\begin{array}{c}113 \\
\text { (organic) }\end{array}$ & $7 \%$ & & [36] \\
\hline & 113 & $6 \%$ & & \\
\hline \multirow[t]{2}{*}{ Austria } & 31 & $\begin{array}{c}\text { 58\% (Euroclone } \\
\text { ELISA) }\end{array}$ & $\begin{array}{c}65 \% \text { by } \\
\text { sedimentation }\end{array}$ & {$[16]$} \\
\hline & & $\begin{array}{c}61 \% \text { (Pourquier } \\
\text { ELISA) }\end{array}$ & $\begin{array}{c}55 \% \text { by } \\
\text { coproantigen } \\
\text { ELISA }\end{array}$ & \\
\hline Germany & 4630 & $51 \%$ & & [54] \\
\hline
\end{tabular}

${ }^{*}$ All herds under conventional management unless otherwise indicated. 
Bennema and colleagues found that in addition to climatic and environmental factors, herd management practices had a major impact [51]. Bulk milk ELISA scores increased with the proportion of fresh grass in the diet and the length of the grazing season, both factors that are directly linked to the exposure to metacercariae, particularly in the autumn when infection levels on pastures peak. Finally, and rather suprisingly, medium-sized herds (30-60 animals) were more likely to be bulk-milk positive than large-sized herds $(>60)$. However, this was thought to be due to confounding, underlying management factors, not addressed in the study.

\section{Prevalence of $F$. hepatica according to bulk milk ELISA}

Bulk milk screening indicated high prevelances of between 50 and $85 \%$ of herds in the UK, Austria and Germany, with intermediate levels in Belgium and low prevalences in both conventional and organic farms in Sweden (Table 5). In Ireland, liver fluke has long been understood to be endemic. A study carried out in 2006 reported the presence of liver flukes in $65 \%$ of livers from culled cattle in Ireland [52].

\section{Lungworm, Dictyocaulus viviparous Life cycle and clinical signs}

Like O. ostertagi, the cattle lungworm, Dictyocaulus viviparus, is a nematode of the trichostrongylid family with a worldwide distribution, although it is most common in temperate regions with high rainfall [24]. The adult female worms are ovo-viviparous and as a result larvae are present in fresh faeces, a feature that is highly unusual in gastrointestinal worms [24]. The migration of the larvae out of the faecal pat and into the herbage is aided by the fungus Pilobolus, which can propel the tiny parasitic larvae over a distance of up to $3 \mathrm{~m}$. Following ingestion, the parasites burrow through the intestinal mucosa and travel via the lymph or blood to the lungs, where they break out of the capillaries into the alveolar spaces. After some further maturation in the bronchioles, the adult lungworms appear in the bronchi. Clinical signs can appear some time before infections become patent (and detectable by faecal analysis). Dictyocaulosis is also known as parasitic bronchitis, and heavy infections are characterised by frequent bouts of coughing and dyspnoea due to widespread lung damage. In endemic areas most animals acquire protective immunity during their first grazing season and as a result, severe clinical signs are usually only observed in very young calves exposed to heavy challenge [24]. In older animals, subclinical or mild to moderate infections are common, and although the level of infection in endemic countries may be high, the number of animals that go on to become clinically affected is lower than those identified as seropositive. In a study on first season grazing cattle herds in northern Germany, it was estimated that infection with the parasite caused clinical disease in approximately one-third of infected cattle [55].

\section{ELISA assays for the detection of $D$. viviparus}

The standard ELISA assay for the detection of $D$. viviparus uses as capture antigen a recombinant major sperm protein (MSP), which is the most immunogenic $D$. viviparus protein identified so far [56,57]. For individual serum and milk samples the recombinant MSP ELISA has a sensitivity of between 97.5 and $99 \%$ and a specificity of over $99 \%$. Significantly, there is no cross reactivity with Ostertagia or Cooperia $[8,13,58]$. Experimental infections indicated that lungworm-specific antibodies were detectable 28 to 35 days post infection (dpi) for a period of between 79 and 107 days [58]. In animals turned out to pasture, ELISA readings exceeded cut-off values at 28 days post turnout. Generally antibody patterns in individual milk samples closely match those in individual serum samples but titres are lower.

For bulk milk samples the MSP ELISA is a useful tool only if the herd is highly infected (during moderate to severe outbreaks) [59]. According to a study of thirtythree farms in the Netherlands, a region with a historically high prevalence of lungworm infection, at least 30\% of the animals in the herd were required to be seropositive before the bulk milk sample exceeded the cut-off.

\section{Association of bulk milk $D$. viviparus antibody levels with production parameters}

The correlation between raised antibody levels according to bulk milk ELISA testing and lungworm infection status of the herd is not well understood. Ploeger and colleagues reported that bulk-tank milk antibody levels reflected the proportion of the herd that showed clinical signs such as coughing and increased respiratory rate [59]. However, bulk milk ELISA results mostly became positive after the onset of disease in the herd and were more closely related to incidence of lungworm-related morbidity than to prevalence of lungworm infection. The authors suggested that this might be due to the fact that the MSP antigen is a protein that is only expressed in the adult stages of the worm. Those authors concluded that the bulk milk ELISA had a role in the investigation of outbreaks of respiratory disease in adult cattle but that further research was needed before it could be routinely used as a monitoring tool in the context of disease prevention.

Recovery from dictyocaulosis can take several weeks to months [24]. During this time animals continue to suffer clinical signs, largely as a result of a persistent inflammatory response to the presence of dead worm material, damaged host tissue and, frequently, secondary bacterial infections. Even fully recovered cattle often show stunted growth. Generally recovered animals are immune to reinfection but exposure to massive larval challenge can 
result in the so-called 'reinfection syndrome'. In this case migrating lungworm larvae stimulate a strong immune response that causes their destruction within the bronchioles before they can mature to adult worms. Resulting bronchiolar obstruction and the formation of lymphoid nodules around the dead larvae cause frequent coughing, tachypnoea and reduction in milk yield. If and in what way bulk milk ELISA can identify mild or subclinical infections has not yet been established. As adult D. viviparous stages are absent in animals with reinfection syndrome, these are not detected using the current MSP ELISA. For this, further research into lungworm antigen, particularly early larval stage antigen, is needed to provide alternative assays.

\section{Effects of management practices on bulk milk D. viviparus antibody levels}

$D$. viviparus resembles $O$. ostertagi in its transmission route and seasonality, characterised by a gradual build-up of infective larvae on pasture over the summer months, and a general die-back during the winter (although some larvae may survive overwinter by migrating down into the soil) [24]. Hence, similar to ostertagiosis, access to pasture, particularly during times of greatest infection pressure, would be expected to be the most important factor affecting bulk milk antibody levels for lungworm. Unfortunately, there are no published studies on the effects of management strategies on D. viviparus on bulk milk ELISA scores. A surveillance study in Sweden reported a higher bulk milk prevalence of $D$. viviparus antibody in organic as compared to conventional dairy farms [36]. However, under Swedish animal welfare legislation all cattle over 6 months of age must have outdoor access for 2 to 4 months during the grazing season, and it is not known whether organically reared animals in the study did in fact spend more time grazing. According to the authors, the main difference between organic and conventional production systems in Sweden is that the prophylactic use of anthelmintics is prohibited in organic herds.

Because D. viviparus elicits a strong adaptive immune response in previously exposed animals, it is generally only calves in their first grazing season that are clinically affected [24]. However, some anthelmintic control strategies used in calves today are thought to be so efficient that many animals remain free from infection until they return to pasture during their second year as heifers. At this point they often suffer clinical disease because due to the lack of antigenic exposure they failed to develop effective immunity in the previous year [59]. It is likely, therefore, that anthelmintic use, particularly prophylaxis, would have a significant effect on antibody levels.

\section{Prevalence of $D$. viviparus according to bulk milk ELISA} The only data available for bulk milk prevalence in Ireland, were collected during an as yet unpublished study carried out in 2009 and 2011 which indicated a herd prevalence of $7 \%$ (Bloemhoff and Sayers, comm.). An abattoir study in Co. Kildare in 2002/2003 revealed first stage larvae in the rectal contents of $14 \%$ of culled dairy and beef cattle [55]. Thus the prevalence in Ireland is similar but perhaps slightly lower than that seen in central Europe (Table 6).

\section{Neospora caninum \\ Life cycle and clinical signs}

Only discovered in 1988, the protozoan parasite Neospora caninum is now known as a major cause of abortion in cattle worldwide $[61,62]$. The dog is the final host and can pass infective oocytes in its faeces from 8-23 days post infection [24]. Cattle become infected by ingesting contaminated feed, water or herbage (exogenous transmission). Infections in adult cattle have little clinical effect, however, in the developing foetus they can cause severe pathology. In pregnant cows the parasites can invade the uterus, where they multiply (as tachyzoites) causing focal lesions at the maternofoetal interface (endogenous transmission). If this occurs early in pregnancy, it is likely to result in mummification and abortion of the foetus. Later on in gestation, calves may be born underweight with severe neurological signs. However, in many cases, calves born to cows infected at a late stage in pregnancy are clinically normal but persistently infected. Parasites in these congenitally infected cattle can recrudesce when they themselves become pregnant, again with potentially lethal effects to the foetus.

Unfortunately, the factors that determine whether a previously infected cow will abort, or will give birth to a sick or healthy calf are poorly understood [63]. Abortion storms, the most dramatic manifestation of neosporosis, when more than $10 \%$ of the cows in a herd abort within a 12 week period, are thought to be caused by exogenous transmission arising from infected dogs (mostly pups) recently introduced to the farm. However, as the incidence of oocyst shedding in dogs is very low, this is a rare occurrence. The most common route of transmission in cattle is by the vertical route from dam to calf (endogenous), resulting in persistently infected calves [64]. Through its

Table 6 Dictyocaulus vivaparus prevalence based on bulk milk assay

\begin{tabular}{lccc}
\hline Country (region) & Number of herds & Prevalence & Reference \\
\hline Belgium & 1,800 & $19.6 \%$ & {$[39]$} \\
Sweden & Organic herds 113 & $18 \%$ & {$[36]$} \\
& Conventional 113 & $9 \%$ & \\
Germany (East Frisia) & 906 & $12.8 \%$ Jan 07 & {$[60]$} \\
& & $6.9 \%$ Sept 08 & \\
& & $6.6 \%$ Nov 08 & \\
\hline
\end{tabular}


effects on fertility, $N$. caninum is thought to reduce milk production in adult dairy cows [24].

\section{ELISA assays for the detection of $N$. caninum}

There are several commercial Neospora ELISA tests that have been validated for bulk milk testing (Table 7). Most of these assays use whole tachyzoite antigen as capture antigen. The notable exception to this is the BioK 192/5 from Jemelle (Belgium), which uses a recombinant protein of the major immunodominant tachyzoite surface antigen. Tachyzoites are the rapidly dividing stages of the parasites that, during the acute phase of the infection, invade the placenta and developing foetus.

Most studies indicated a strong correlation between individual seroprevalences and bulk milk results $[6,64-66,68]$, except that higher milk ELISA results are usually found at later stages of lactation as compared with the serum ELISA [69]. Generally about 10 to $15 \%$ of the animals in a herd must be seropositive for the bulk milk result to exceed the cut-off $[23,66,68]$. However, some workers found that bulk milk testing under reported prevalences [70,71]. As with other bulk milk assays, antibody levels in the bulk milk tank are not only dependent on the proportion of infected cows but also their antibody levels, lactation stage and milk yield $[66,72]$. These variables are likely to be more significant in small herds, where the introduction of one or two highly seropositive animals could convert the bulk milk sample. On the other hand, if most individual antibody levels are only just above the cut-off, bulk milk results might be negative even if more than $15 \%$ of animals are infected. In spite of these drawbacks, bulk milk ELISA testing is considered an effective tool in tracking $N$. caninum prevalence at herd level [68], particularly since control measures for the disease currently focus on minimising the seroprevalence within herds [23].

\section{Association of bulk milk N. caninum antibody levels with production parameters}

The effects of $N$. caninum infection on milk yield are not clear-cut. While some studies report reduced milk production in seropositive cows, others observed no association between milk yield and individual serostatus (reviewed in [47]). At herd level, a negative association has been reported between average milk production and ELISA values for bulk-tank milk, with an average loss of $1.6 \mathrm{~kg} / \mathrm{cow} /$ day in highly positive herds compared to seronegative or low positive herds [47]. Furthermore, risk of abortion in seropositive cows is between 2 and 26 times higher than in seronegative cows [64,73-76]. Significantly, this correlation was also observed in relation to bulk milk: a study of over 3200 herds in the German state of Rhineland-Palatine reported that the annual rate of abortion was 3\% higher in farms that were bulk milk positive than in negative farms [69]. This strongly indicates that knowledge of the levels of exposure and herd history on N. caninum may inform prediction of abortion risk, however, this may be most relevant in regions with a very high prevalence of $N$. caninum [23].

\section{Effects of management practices on bulk milk $N$. caninum antibody levels}

The number of dogs on the farm and dog density in the surrounding area have been identified as the most significant risk factors for bulk milk prevalence [77]. At the same time, it must be remembered that the most common route of transmission in cattle is transplacental transmission from dam to calf. Since no effective treatment is available to prevent either abortion or transplacental transmission, the only management practice open to the farmer is not to breed from seropositive animals. It is to be expected, therefore, that selective breeding together with restricting canine access would, over time, lead to a reduction in antibody levels in the bulk milk sample of a herd, but to our knowledge there are no published records.

\section{Prevalence of $N$. caninum according to bulk milk ELISA}

Most of what we know about the prevalence of $N$. caninum-induced abortions in Ireland is gleaned from

Table 7 ELISA assays for the detection of $\boldsymbol{N}$. caninum in cattle bulk milk samples

\begin{tabular}{|c|c|c|c|c|}
\hline ELISA assay & Capture antigen & $\begin{array}{c}\text { Sensitivity } \\
\text { (95\% confidence interval) }\end{array}$ & $\begin{array}{c}\text { Specificity } \\
\text { (95\% confidence interval) }\end{array}$ & Reference \\
\hline \multirow{2}{*}{$\begin{array}{c}\text { ISCOM ELISA (Boehringer Ingelheim Svanova, } \\
\text { Uppsala Sweden) }\end{array}$} & \multirow{2}{*}{$\begin{array}{l}\text { Tachyzoite antigen mixed } \\
\text { with iscoms }{ }^{1}\end{array}$} & $50 \%$ & $81 \%$ & \multirow[t]{2}{*}{ [65] } \\
\hline & & $(21-79 \%)$ & $(72-89 \%)$ & \\
\hline \multirow[t]{2}{*}{ IDEXX Neospora antibody test } & \multirow[t]{2}{*}{ Whole sonicated tachyzoites } & $61 \%$ & $92 \%$ & \multirow[t]{2}{*}[66]{} \\
\hline & & $(49-73 \%)$ & (87-98\%) & \\
\hline \multirow[t]{2}{*}{ LSI ELISA (Lissieu, France) } & \multirow{2}{*}{$\begin{array}{c}\text { Whole tachyzoite crude } \\
\text { antigen lysate }\end{array}$} & $47 \%$ & $94 \%$ & \multirow[t]{2}{*}{ [66] } \\
\hline & & $(35-60 \%)$ & (90-99\%) & \\
\hline Mastazyme ${ }^{\oplus}$ ELISA (Mast Diagnostics UK) & Whole tachyzoites & $61-78 \%$ & $75-96 \%$ & {$[67]$} \\
\hline BioK 192/5, Jemelle, Belgium & Recombinant NcSRS2 protein & $95 \%$ & $96 \%$ & [7] \\
\hline
\end{tabular}

${ }^{1}$ Immunostimulatory complex composed of quillaja saponin, cholesterol and phospholipids. 
clinical pathology findings. According to the All Ireland Animal Surveillance Disease Report, 2011, 5.3\% of aborted foetuses in the Republic and 7.7\% in Northern Ireland tested positive for $N$. caninum either serologically, by histopathology or immunohistochemistry [78]. Earlier surveys from the Regional Veterinary Lab in Kilkenny reported that $7 \%$ of foetuses and $14 \%$ of recently aborted cows submitted for abortion between 1999 and 2003 were serologically positive for $N$. caninum [79]. These figures are significantly lower than those reported for the UK in general where $27 \%$ of diagnosed abortions were attributable to $N$. caninum [80]. Unfortunately, no published reports are available regarding $N$. caninum prevalence as determined by bulk milk assay. However, in-house testing on behalf of herd owners indicate that the prevalence is approximately 9\%, (based on 2,200 bulk milk samples tested in three rounds) in 2011 and 2012 (Sekiya M., unpublished). Table 8 lists prevalences worldwide and indicates that rates are highest in warmer climates. Further surveillance and monitoring may lead to models associating climate with levels of Neospora occurrence.

\section{Conclusions and future prospects}

Dairy herd health management involves establishing and maintaining optimal animal health and productivity. The basic steps in delivery and execution of herd health management are cyclical. Initially farm goals and targets are defined, then herd performance in key areas is monitored and compared to agreed targets. Where shortfalls are identified, investigative protocols are employed to identify the cause and appropriate control strategies implemented. The effects of these controls on farm performance are monitored and thus the cycle begins again (Figure 1) [82]. This concept is central to all aspects of herd health management including parasite control. A dairy herd parasite control programme must be tailored for the individual farm taking animal health and production, farm-specific management, grazing history and seasonal conditions into consideration.

It is clear that bulk milk testing has a potential role in both the monitoring and investigative aspects of the herd health management cycle (Figure 1). However, its role needs to be seen in the context of the other key components of optimal parasite management in the dairy herd such as those outlined by the parasite control TWG/AHI [83].

Thus, the data from regular (at least 3-4 times/year depending on the calving pattern) bulk milk screening needs to assessed in the context of the other key components of parasite control including risk-based assessment of pasture contamination, judicious use of faecal testing as well as follow-up inspection of tissue (liver, lung, abomasum etc.) at post-mortem examination as well as in
Table 8 Neospora caninum prevalence based on bulk milk assay

\begin{tabular}{|c|c|c|c|}
\hline Country (region) & $\begin{array}{c}\text { Number of } \\
\text { herds }\end{array}$ & Prevalence & Reference \\
\hline $\begin{array}{l}\text { Thailand (North and } \\
\text { Northeast) }\end{array}$ & 220 & $46 \%$ & [72] \\
\hline Sweden & 2,978 & $\begin{array}{c}8.3 \% \\
(95 \% \text { Cl, } 7.3-9.3 \%)\end{array}$ & [70] \\
\hline Norway & 1,657 & $\begin{array}{c}0.7 \% \\
(95 \% \mathrm{Cl}, 0.3-1.2 \%)\end{array}$ & [81] \\
\hline \multirow[t]{3}{*}{ Canada } & 235- May 04 & $6.4 \%$ & {$[68]$} \\
\hline & 189- May 05 & $10.1 \%$ & \\
\hline & 235- June 05 & $10.2 \%$ & \\
\hline Australia (South) & 122 & $\begin{array}{c}2.5 \% \\
(95 \% \mathrm{Cl}, 1.4-3.6 \%)\end{array}$ & [71] \\
\hline Spain (Galicia) & 276 & $56 \%$ & [23] \\
\hline
\end{tabular}

the context of abattoir surveillance. The bulk milk data could be viewed as one of the tools in the kit of the dairy herd veterinarian to facilitate decision-making at farm level.

Ostertagiosis makes its greatest economic impact (clinical and subclinical disease) in the context of first and second-grazing season calves and the decision to treat adult cows to improve milk yield must always be based on a proper cost-benefit analysis, whilst taking issues of anthelmintic resistance into consideration [84]. A bulk milk test for O. ostertagi antibodies at the end of

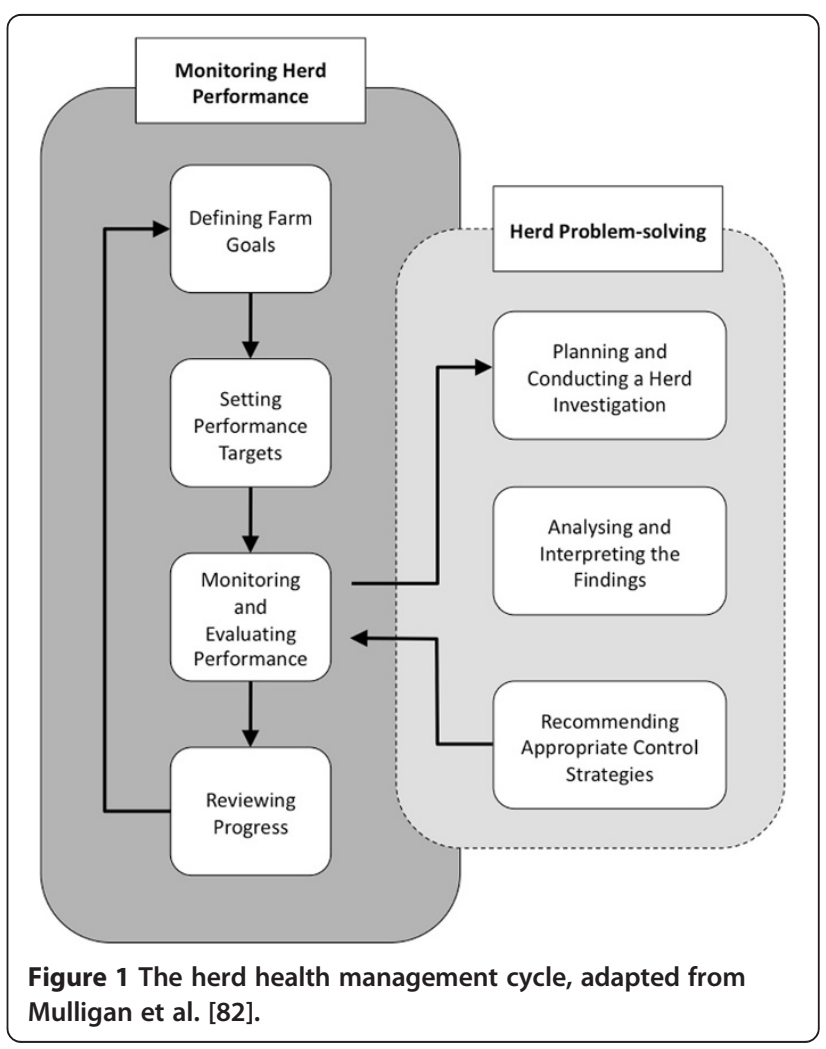


a grazing season in the adult herd may assist the planning of worm control strategies for replacement heifers in the next season [85]. Thus, a test with a low titre at the end of the grazing season in the adult herd may indicate that exposure of first-grazing season animals that year was not sufficient to stimulate adequate immunity going into the second season.

Bulk milk monitoring is used to detect infections that are subclinical, yet result in increased costs to the herd owner primarily in terms of decreased milk yield and potentially, to a lesser extent, cattle weight gain, milk quality and reproductive fitness [22]. It is an effective diagnostic indicator of exposure to moderate to high levels of parasitic infections and can provide an indication of intensity of infection in the herd in endemic situations [23,33]. Finally, it has been investigated as an indicator for the effectiveness of parasiticide prophylaxis or treatment [22], bearing in mind, however, that antibody titres can remain high after treatment and that in these situations information provided by bulk milk testing needs to be considered carefully. As such bulk milk testing can inform costbenefit analysis and treatment decisions. An added advantage of bulk milk testing is that the same samples that are already routinely collected by the dairy industry for milk quality testing can be used.

The application of bulk milk ELISA as a predictive tool for risks associated with parasite infection is still at an early stage, the extent of research findings varies with the parasite species in question. For $O$. ostertagi, liver fluke and lungworm, the risk of acquiring the parasite is linked to grazing on contaminated pasture. Bulk milk assay will give a good indication of current exposure if employed as part of an ongoing herd health surveillance programme. On the other hand, data from less frequent testing may be difficult to interpret as anti-parasite antibodies can persist for a long time post treatment (depending on assay). Available prevalence data from Ireland indicate that any herd on pasture is at risk of acquiring infection. The question then becomes: How severe is the herd level infection?

For O. ostertagi, bulk milk assay can be effective in providing thresholds that may be converted to predicted milk loss per cow per day [19]. For liver fluke, the risk is highly dependent on the environment and is linked to grazing on contaminated pasture. For lungworm, there is an advantage of knowing levels of exposure and how this might contribute to respiratory disease incidence. For Neospora, high levels of bulk milk antibodies may contribute to greater risk of abortion [23] and would indicate that Neospora should be considered as a cause in unusual patterns of abortion.

Bulk milk results contribute to building risk assessment models. An active area of research is the development of software models for the risk for infection and disease spread with a GIS based system, using prevalence data based on bulk milk assay in combination with other environmental factors including weather data and soil conditions $[28,86,87]$. One such programme is ParaCalc ${ }^{\circ}$, a spread-sheet model that calculates the effects of infections on production and the cost of the production losses, based on diagnostic assays of herd health and anthelmintic usage. The programme was tested during a study of Belgian dairy herds [88]. The results indicated an estimated median cost of infection with gastrointestinal nematodes of $€ 46$ per cow per year, with a much lower estimated cost of $€ 6$ for liver fluke. The most significant factor was reduced milk production in infected cows.

Integration of bulk milk assay results and other clinical findings in an easy to use application would be a tremendous advantage for both farmers and herd health management professionals. Future developments in bulk milk assay will likely include multiplexing platforms that facilitate the assay of several parasitic infections at one time and point-of-care or pen-side tests that provide an immediate result for the herd.

The bulk milk ELISA can be a useful tool for the veterinary practitioner as a component of a herd health monitoring programme or in the context of a herd health investigation. However, the results of bulk milk testing for gutworm, liver fluke and lungworm simple indicate the presence (or absence) of antibodies from prior or current exposure and do not necessarily indicate active infection or disease. Therefore, like all diagnostic tests, antibodies in bulk milk should be assessed with reference to the holistic herd health picture and not used as the only discriminator in the decision-making process with regards to both potential economic losses and response to treatment.

\section{Competing interests}

The authors declare that they have no competing interests.

\section{Authors' contributions}

MD conceived the idea for the review and provided the herd health narrative. AZ provided the content relating to parasitology. MS provided the content relating to the diagnostic techniques. All authors read and approved the final manuscript.

\section{Acknowledgements}

Support from Animal Health Ireland and the Technical Working Group for parasite control for Animal Health Ireland.

Received: 25 April 2013 Accepted: 27 June 2013

Published: 25 July 2013

\section{References}

1. More SJ, Doherty ML, Downey L, McKenzie K, Devitt C, O'Flaherty J: Animal Health Ireland: providing national leadership and coordination of nonregulatory animal health issues in Ireland. Rev Sci Tech OIE 2011, 30:715-723.

2. More SJ, McKenzie K, O'Flaherty J, Doherty ML, Cromie AR, Magan MJ: Setting priorities for non-regulatory animal health in Ireland: results from an expert Policy Delphi study and a farmer priority identification survey. Prev Vet Med 2010, 95:198-207. doi:10.1016/j.prevetmed.2010.04.011

3. Niskanen R: Relationship between the levels of antibodies to bovine viral diarrhoea virus in bulk tank milk and the prevalence of cows exposed to the virus. Vet Rec 1993, 133:341-344. 
4. Forschner E, Bunger I, Kuttler D, Merkhens L: IBR/IPV - Serologic Diagnosis, Using Blood-Samples, Single Milk Samples and Bulk Milk Samples, Control of Cattle Herds Eradication by Separation or Vaccination. Deut Tierarztl Woch 1986, 93:328-335.

5. Hoorfar J, Lind P, Bitsch V: Evaluation of an $\mathrm{O}$ antigen enzyme-linked immunosorbent assay for screening of milk samples for Salmonella dublin infection in dairy herds. Can J Vet Res 1995, 59:142-148.

6. Björkman C, Holmdahl OJ, Uggla A: An indirect enzyme-linked immunoassay (ELISA) for demonstration of antibodies to Neospora caninum in serum and milk of cattle. Vet Parasitol 1997, 68:251-260.

7. Borsuk $S$, Andreotti $R$, Leite FPL, Pinto LDS, Simionatto $S$, Hartleben $C P$, Goetze M, Oshiro LM, Matos MDFC, Berne MEA: Development of an indirect ELISA-NcSRS2 for detection of Neospora caninum antibodies in cattle. Vet Parasitol 2011, 177:33-38.

8. Schnieder T: Use of a Recombinant Dictyocaulus-viviparus Antigen in an Enzyme-linked-Immunosorbent-Assay for Immunodiagnosis of Bovine Dictyocaulosis. Parasitol Res 1992, 78:298-302.

9. Collins PR, Stack CM, O'Neill SM, Doyle S, Ryan T, Brennan GP, Mousley A, Stewart M, Maule AG, Dalton JP, Donnelly S: Cathepsin L1, the major protease involved in liver fluke (Fasciola hepatica) virulence: propetide cleavage sites and autoactivation of the zymogen secreted from gastrodermal cells. J Biol Chem 2004, 279:17038-17046.

10. Crowther JR: ELISA Theory and Practice. Totowa, New Jersey, USA: Humana Press Inc; 1995:223.

11. Greiner M, Pfeiffer D, Smith RD: Principles and practical application of the receiver-operating characteristic analysis for diagnostic tests. Prev Vet Med 2000, 45:23-41.

12. Greiner M, Gardner I a: Epidemiologic issues in the validation of veterinary diagnostic tests. Prev Vet Med 2000, 45:3-22.

13. Fiedor C, Strube C, Forbes A, Buschbaum S, Klewer A-M, Von SamsonHimmelstjerna G, Schnieder T: Evaluation of a milk ELISA for the serodiagnosis of Dictyocaulus viviparus in dairy cows. Vet Parasitol 2009, 166:255-261.

14. Butler JE: Bovine immunoglobulins - an augmented review. Vet Immunol Immunop 1983, 4:43-152.

15. Gapper LW, Copestake DEJ, Otter DE, Indyk HE: Analysis of bovine immunoglobulin $\mathrm{G}$ in milk, colostrum and dietary supplements: a review. Anal Bioanal Chem 2007, 389:93-109.

16. Duscher R, Duscher G, Hofer J, Tichy A, Prosl H, Joachim A: Fasciola hepatica - monitoring the milky way? The use of tank milk for liver fluke monitoring in dairy herds as base for treatment strategies. Vet Parasitol 2011, 178:273-278.

17. Salimi-Bejestani MR, McGarry JW, Felstead S, Ortiz P, Akca a, Williams DJL, Salimi Bejestani M: Development of an antibody-detection ELISA for Fasciola hepatica and its evaluation against a commercially available test. Res Vet Sci 2005, 78:177-181.

18. Reichel MP, Vanhoff K, Baxter B: Performance characteristics of an enzymelinked immunosorbent assay performed in milk for the detection of liver fluke (Fasciola hepatica) infection in cattle. Vet Parasitol 2005, 129:61-66.

19. Forbes $A B$, Charlier J: Bulk milk ELISAs for quantitative estimates of parasite infection. Cattle Pract 2006, 14:167-173.

20. Cripps P, Williams DJL: Evaluation of an ELISA to assess the intensity of Fasciola hepatica infection in cattle. Vet Rec 2008, 162:109-111.

21. Charlier J, Duchateau L, Claerebout E, Vercruysse J: Predicting milkproduction responses after an autumn treatment of pastured dairy herds with eprinomectin. Vet Parasitol 2007, 143:322-328.

22. Vercruysse J, Claerebout E: Treatment vs non-treatment of helminth infections in cattle: defining the threshold. Vet Parasitol 2001, 98:195-214.

23. González-Warleta M, Castro-Hermida JA, Carro-Corral C, Mezo M: AntiNeospora caninum antibodies in milk in relation to production losses in dairy cattle. Prev Vet Med 2011, 101:58-64.

24. Taylor MA, Coop RL, Wall RL: Veterinary Parasitology. Third. Oxford UK: Blackwell Publishing Itd; 2007

25. Charlier J, Claerebout E, De Mûelenaere E, Vercruysse J: Associations between dairy herd management factors and bulk tank milk antibody levels against Ostertagia ostertagi. Vet Parasitol 2005, 133:91-100.

26. Kloosterman A, Verhoeff J, Ploeger HW, Lam T: Antibodies Against Nematodes in Serum, Milk and Bulk Milk Samples as Possible Estimators of Infection in Dairy-Cows. Vet Parasitol 1993, 47:267-278.

27. Blanco-Penedo I, Höglund J, Fall N, Emanuelson U: Exposure to pasture borne nematodes affects individual milk yield in Swedish dairy herds. Vet Parasitol 2012, 188:93-98.
28. Bennema SC, Vercruysse J, Morgan E, Stafford K, Höglund J, Demeler J, Von Samson-Himmelstjerna G, Charlier J: Epidemiology and risk factors for exposure to gastrointestinal nematodes in dairy herds in northwestern Europe. Vet Parasitol 2010, 173:247-254

29. Forbes AB, Vercruysse J, Charlier J: A survey of the exposure to Ostertagia ostertagi in dairy cow herds in Europe through the measurement of antibodies in milk samples from the bulk tank. Vet Parasitol 2008, 157:100-107.

30. Guitián FJ, Dohoo IR, Markham RJ, Conboy G, Keefe GP: Relationships between bulk-tank antibodies to Ostertagia ostertagi and herdmanagement practices and measures of milk production in Nova Scotia dairy herds. Prev Vet Med 1999, 47:79-89.

31. Sanchez J, Dohoo I: A bulk tank milk survey of Ostertagia ostertagi antibodies in dairy herds in Prince Edward Island and their relationship with herd management factors and milk yield. Can Vet J La revue vétérinaire canadienne 2002, 43:454-459.

32. Almería S, Adelantado C, Charlier J, Claerebout E, Bach A: Ostertagia ostertagi antibodies in milk samples: relationships with herd management and milk production parameters in two Mediterranean production systems of Spain. Res Vet Sci 2009, 87:416-420.

33. Charlier J, Claerebout E, Duchateau L, Vercruysse J: A survey to determine relationships between bulk tank milk antibodies against Ostertagia ostertagi and milk production parameters. Vet Parasitol 2005, 129:67-75.

34. Charlier J, De Cat A, Forbes A, Vercruysse J: Measurement of antibodies to gastrointestinal nematodes and liver fluke in meat juice of beef cattle and associations with carcass parameters. Vet Parasitol 2009, 166:235-240.

35. Vanderstichel R, Dohoo I, Sanchez J, Conboy G: Effects of farm management practices and environmental factors on bulk tank milk antibodies against gastrointestinal nematodes in dairy farms across Canada. Prev Vet Med 2012, 104:53-64.

36. Höglund J, Dahlström F, Engström A, Hessle A, Jakubek E-B, Schnieder T, Strube C, Sollenberg S: Antibodies to major pasture borne helminth infections in bulk-tank milk samples from organic and nearby conventional dairy herds in south-central Sweden. Vet Parasitol 2010, 171:293-299.

37. Sanchez J, Nodtvedt A, Dohoo I, DesCôteaux L: The effect of eprinomectin treatment at calving on reproduction parameters in adult dairy cows in Canada. Prev Vet Med 2002, 56:165-177.

38. Charlier J, Camuset P, Claerebout E, Courtay B, Vercruysse J: A longitudinal survey of anti-Ostertagia ostertagi antibody levels in individual and bulk tank milk in two dairy herds in Normandy. Res Vet Sci 2007, 83:194-197.

39. Bennema S, Vercruysse J, Claerebout E, Schnieder T, Strube C, Ducheyne E, Hendrickx G, Charlier J: The use of bulk-tank milk ELISAs to assess the spatial distribution of Fasciola hepatica, Ostertagia ostertagi and Dictyocaulus viviparus in dairy cattle in Flanders (Belgium). Vet Parasitol 2009, 165:51-57.

40. Levieux D, Levieux A, Mage C, Venien A: Early Immunodiagnosis of Bovine Fascioliasis using the Specific Antigen- $\mathrm{f} 2$ in a Passive Hemagglutination Test. Vet Parasitol 1992, 44:77-86.

41. Mezo M, González-Warleta M, Castro-Hermida J a, Muiño L, Ubeira FM: Field evaluation of the MM3-SERO ELISA for detection of anti-Fasciola lgG antibodies in milk samples from individual cows and bulk milk tanks. Parasitol Int 2010, 59:610-615.

42. Lightowlers MW, Rickard MD: Excretory Secretory Products of HelminthParasites -Effects on Host Immune-Responses. Parasitology 1988, 96:S123-S166.

43. Reichel MP: Performance characteristics of an enzyme-linked immunosorbent assay for the detection of liver fluke (Fasciola hepatica) infection in sheep and cattle. Vet Parasitol 2002, 107:65-72.

44. Mezo M, González-Warleta M, Ubeira FM: The use of MM3 monoclonal antibodies for the early immunodiagnosis of ovine fascioliasis. J Parasitol 2007, 93:65-72.

45. Salimi-Bejestani M, Felstead SM, Mahmoody H, Williams DJL, Daniel R, Cripps P: Prevalence of Fasciola hepatica in dairy herds in England and Wales measured with an ELISA applied to bulk-tank milk. Vet Rec 2005, 156:729-731.

46. Charlier J, Duchateau L, Claerebout E, Williams D, Vercruysse J: Associations between anti-Fasciola hepatica antibody levels in bulk-tank milk samples and production parameters in dairy herds. Prev Vet Med 2007, 78:57-66.

47. Mezo M, González-Warleta M, Castro-Hermida JA, Muiño L, Ubeira FM: Association between anti-F. hepatica antibody levels in milk and production losses in dairy cows. Vet Parasitol 2011, 180:237-242. 
48. Black NM, Froyd G: Possible influence of liver fluke infestation on milk quality. Vet Rec 1972, 90:71-72.

49. Kaplan RM: Fasciola hepatica: a review of the economic impact in cattle and considerations for control. Vet Ther 2001, 2:40-50. winter.

50. Claridge J, Diggle P, McCann CM, Mulcahy G, Flynn R, McNair J, Strain S, Welsh M, Baylis M, Williams DJL: Fasciola hepatica is associated with the failure to detect bovine tuberculosis in dairy cattle. Nat Commun 2012, 3:853.

51. Bennema SC, Ducheyne E, Vercruysse J, Claerebout E, Hendrickx G, Charlier $\mathrm{J}$ : Relative importance of management, meteorological and environmental factors in the spatial distribution of Fasciola hepatica in dairy cattle in a temperate climate zone. Int J Parasitol 2011, 41:225-233.

52. Murphy TM, Fahy KN, Mcauliffe A, Forbes AB, Clegg TA: A study of helminth parasites in culled cows from Ireland. Prev Vet Med 2006, 76:1-10.

53. Pritchard GC, Forbes AB, Williams DJL, Salimi-bejestani MR, Daniel R: Emergence of fasciolosis in cattle in East Anglia. Vet Rec 2005, 157:578-582.

54. Kuerpick B, Schnieder T, Strube C: Seasonal pattern of Fasciola hepatica antibodies in dairy herds in Northern Germany. Parasitol Res 2012, 111:1085-1092.

55. Schneider T, Bellmer A, Tenter AM: Seroepidemiological study on dictyocaulus-viviparus infections in 1st year grazing cattle in Northern Germany. Vet Parasitol 1993, 47:289-300.

56. DeLeeuw WA, Cornelissen J: Identification and isolation of a specific antigen with diagnostic potential from dictyocaulus-viviparus. Vet Parasitol 1991, 39:137-147.

57. Tenter AM, Bellmer A, Schneider T: Evaluation of an ELISA for Dictyocaulusviviparus-Specific Antibodies in Cattle. Vet Parasito/ 1993, 47:301-314.

58. Von Holtum C, Strube C, Schnieder T, Von Samson-Himmelstjerna G: Development and evaluation of a recombinant antigen-based ELISA for serodiagnosis of cattle lungworm. Vet Parasitol 2008, 151:218-226.

59. Ploeger HW, Verbeek PC, Dekkers CWH, Strube C, Van Engelen E, Uiterwijk M, Lam TJGM, Holzhauer M: The value of a bulk-tank milk ELISA and individual serological and faecal examination for diagnosing (sub)clinical Dictyocaulus viviparus infection in dairy cows. Vet Parasitol 2012, 184:168-179.

60. Klewer A-M, Forbes A, Schnieder T, Strube C: A survey on Dictyocaulus viviparus antibodies in bulk milk of dairy herds in Northern Germany. Prev Vet Med 2012, 103:243-245.

61. Dubey JP, Schares G: Diagnosis of bovine neosporosis. Vet Parasitol 2006, 140:1-34.

62. Dubey JP, Schares G: Neosporosis in animals-the last five years. Vet Parasitol 2011, 180:90-108.

63. Williams DJL, Hartley CS, Björkman C, Trees a J: Endogenous and exogenous transplacental transmission of Neospora caninum - how the route of transmission impacts on epidemiology and control of disease. Parasitology 2009, 136:1895-1900.

64. Pare J, Thurmond MC, Hietala SK: Congenital Neospora caninum infection in dairy cattle and associated calfhood mortality. Can J Vet Res 1996, 60:133-139.

65. Frössling J, Lindberg A, Björkman C: Evaluation of an iscom ELISA used for detection of antibodies to Neospora caninum in bulk milk. Prev Vet Med 2006, 74:120-129.

66. Bartels CJM, Van Maanen C, Van der Meulen AM, Dijkstra T, Wouda W: Evaluation of three enzyme-linked immunosorbent assays for detection of antibodies to Neospora caninum in bulk milk. Vet Parasito/ 2005, 131:235-246.

67. Milne E, Crawshaw M, Brocklehurst S, Wright S, Maley S, Innes E: Associations between Neospora caninum specific antibodies in serum and milk in two dairy herds in Scotland. Prev Vet Med 2006, 77:31-47.

68. Wapenaar W, Barkema HW, O'Handley RM, Bartels CJM: Use of an enzymelinked immunosorbent assay in bulk milk to estimate the prevalence of Neospora caninum on dairy farms in Prince Edward Island, Canada. Can Vet J 2007, 48:493-499.

69. Schares G, Staubach C, Wurm R, Rauser M, Conraths FJ, Schroeder C: Adaptation of a commercial ELISA for the detection of antibodies against Neospora caninum in bovine milk. Vet Parasitol 2004, 120:55-63.

70. Frössling J, Nødtvedt A, Lindberg A, Björkman C: Spatial analysis of Neospora caninum distribution in dairy cattle from Sweden. Geospat Health 2008, 3:39-45.

71. Nasir A, Lanyon SR, Schares G, Anderson ML, Reichel MP: Sero-prevalence of Neospora caninum and Besnoitia besnoiti in South Australian beef and dairy cattle. Vet Parasitol 2012, 186:480-485.
72. Chanlun A, Näslund K, Aiumlamai S, Björkman C: Use of bulk milk for detection of Neospora caninum infection in dairy herds in Thailand. Vet Parasitol 2002, 110:35-44

73. Thurmond MC, Hietala SK: Effect of congenitally acquired Neospora caninum infection on risk of abortion and subsequent abortions in dairy cattle. Amer J Vet Res 1997, 58:1381-1385.

74. Garcia-Vazquez Z, Rosario-Cruz R, Ramos-Aragon A, Cruz-Vazquez C, MapesSanchez G: Neospora caninum seropositivity and association with abortions in dairy cows in Mexico. Vet Parasitol 2005, 134:61-65.

75. Koiwai M, Hamaoka T, Haritani M, Shimizu S, Kimura K, Yamane I: Proportion of abortions due to neosporosis among dairy cattle in Japan. J Vet Med Sci 2005, 67:1173-1175.

76. Weston JF, Williamson NB, Pomroy WE: Associations between pregnancy outcome and serological response to Neospora caninum among a group of dairy heifers. New Zeal Vet J 2005, 53:142-148.

77. Schares G, Barwald AB, Staubach C, Ziller M, Kloss D, Schroder R, Labohm R, Drager K, Fasen W, Hess RG, Conraths FJ: Potential risk factors for bovine Neospora caninum infection in Germany are not under the control of the farmers. Parasitology 2004, 129:301-309.

78. AFBI, DAFM: All-island animal disease surveillance report, 2011. A joint AFBI/ DAFM Veterinary Laboratories Publication. Republic of Ireland: Agri-food and Biosciences Institute, Northern Ireland and Department of Agriculture, Food and the Marine [http://www.agriculture.gov.ie/press/pressreleases/2012/ november/title,67833,en.html]

79. Toolan DP: Neospora caninum abortion in cattle - a clinical perspective. Irish Vet J 2003, 56:404-410.

80. Animal Health and Veterinary Laboratories Agency: Veterinary Investigation Surveillance Report (VIDA); 2008 [http://www.defra.gov.uk/ahvla-en/ publication/vida08/]

81. Klevar S, Norström M, Tharaldsen J, Clausen T, Björkman C: The prevalence and spatial clustering of Neospora caninum in dairy herds in Norway. Vet Parasitol 2010, 170:153-157.

82. Mulligan FJ, O'Grady L, Rice DA, Doherty ML: A herd health approach to dairy cow nutrition and production diseases of the transition cow. Anim Reprod Sci 2006, 96:331-353.

83. Animal Health Ireland: A Guide to Parasite control at turn-out. Parasite Control Leaflet Series Number 2, Version 1. Ireland; 2011 [http://www. animalhealthireland.ie]

84. Taylor MA: COWS-Control of Worms Sustainably. A technical manual for veterinary surgeons and advisors. Kenilworth, UK: Agriculture and Horticulture Development Board; 2010

85. Breen J, Down P, Kerby M, Bradley A: Restoring the Dairy Herd: Rearing Youngstock and Replacing Cows. In Dairy Herd Health. Edited by Green M. UK: CABI; 2012:44-66.

86. McCann CM, Baylis M, Williams DJL: Seroprevalence and spatial distribution of Fasciola hepatica-infected dairy herds in England and Wales. Vet Rec 2010, 166:612-617.

87. Charlier J, Bennema SC, Caron Y, Counotte M, Ducheyne E, Hendrickx G, Vercruysse J: Towards assessing fine-scale indicators for the spatial transmission risk of Fasciola hepatica in cattle. Geospat Health 2011, 5:239-245.

88. Charlier J, Van der Voort M, Hogeveen $\mathrm{H}$, Vercruysse J: ParaCalc ${ }^{\circledR}$-a novel tool to evaluate the economic importance of worm infections on the dairy farm. Vet Parasitol 2012, 184:204-211.

\section{doi:10.1186/2046-0481-66-14}

Cite this article as: Sekiya et al:: Bulk milk ELISA and the diagnosis of parasite infections in dairy herds: a review. Irish Veterinary Journal 2013 66:14 